\title{
A perspective on our industry - Waitangi Fellowship Report
}

\author{
ROBDN CAMPBELL \\ Fraser Road, Lochiel, 1 RD, Winton
}

\begin{abstract}
The management practices in common use in the sheep industries of UK and New Zealand have few similarities, This is the inevitable result of the widely different political. climatic and financial influences the two industries experience. New Zealand products enjoy a favonrableresponse from British consumers. They are considered to be quality items and generally look well in the markets. Our markets are well established and while we would all acknowledge imperfections, there are now more important issues than philosophy and structure. Returns to the producer is the paramount problem in the New Zealand sheep industry. A long term approach to that issue may demand considerable investment in the market place, delaying the flow of the entire amount of increased return back to farmers. The New Zealand farmer is a more innovative and adaptable character than his British counterpart. At least part of this is due to the volumes of regulations and restrictions that plague British farmers. Herein lies an asset that we should exploit to maintain a competitive edge.
\end{abstract}

Keywords New Zealand, sheep industry,United Kingdom

When I accepted the Fellowship which has provided the bulk of thematerial for this address, I knew that the main objective was to foster understanding between the sheep industries of the UK and New Zealand. But I did not realise how great the differences or the misunderstandings are, and neither did I realise the importance of focusing upon the matter.

For anyone accustomed to a single breed flock and home-bred replacements. the British sheep industry presents a confusing picture. A system has evolved which links the whole industry in a stratified flock. The system is based upon the hardy hill breeds like the Scottish Blackface. Those who farm in the hills dispose of their cast stock to the easier uplands where they will be crossed with a sire that will add prolificacy and milking ability. A favourite sire for this purpose is the Blue-faced Leicester. The female progeny are known generally as, 'mules' and are sold on to the highly productive land to be mated with a terminal sire that will add conformation and thus a lamb suitable for the market. Put like that it sounds simple, but when a dozen variations upon the theme are added, I found I had to ask the owner what breed of sheep I was looking at.

The British farmers are proud of this system and most will debate it $\mathrm{s}$ merits with enthusiasm. It provides the hill farmer with a valuable outlet for his stock, and the crossing adds a measure of hybrid vigour. However, the breeding of the mule ewe does result in the production of some mule and hill breed wethers of poor conformation. and the linking of the whole flock has been associated with the spread of disease. A New Zealander might be concerned at the size of the stud flocks. Because commercial production is based upon cross breeds, the stud flocks are small, some have only 15 ewes. and selection pressure is virtually nil.

Regardless of what we may think of this system, it is a rational response to the circumstances in which British farmers operate. They plan for a long bleak winter. Whether it is much longer or much bleaker than ours we may debate, but it's true that Southland is closer to the equator than any part of the UK. It is the warmth of the gulf stream that makes the difference for them. Trees grow with less vigour than ours. and 300 metres of altitude in the UK is said to have a similar influence to a 1000 metre change here. The UK farming industry revolves around silage. They are either making it. feeding it, or spreading the resultant slurry. Animals are inside for various lengths of time. depending on the area. Six months inside is common and 305 days for a dairy herd in Germany was the most extensive use of housing I saw.

In New Zealand terms UK farmers were getting about $\$ 93$ for $20 \mathrm{~kg}$ lambs and in addition to that will get a ewe premium for their first 500 ewes of perhaps $\$ 45$, plus a Less Favoured Area grant and a Hill Land Compensatory Payment if they are applicable. One study of hill farms in UK showed the subsidies they received to be $120 \%$ the value of their production. But farmers never get rich, they just intensify into higher cost production and pay more for land. Any retreat from this situation is painful and despite the figures I have quoted UK farmers are feeling the pressure. Industries in retreat need a scapegoat and NZ has been the target of some quite bitter criticism in recent months. We are blamed for the decline in the price of lamb early this year and it was not always comfortable to be Kiwi. 
Against that background we should turn our attention to the issues that affect NZ producers. The first is the overall perception of our products. I was delighted to find the name New Zealand associated with quality, irrespective of whether the product was lamb, wool, dairy, wine or apples. This is of particular significance for lamb, because not so long ago we were having coldshortening problems which were affecting tenderness, and industrial disputes were affecting deliveries. We were in danger of being identified as the unreliable suppliers of poor quality product. To have turned that around should be regarded as a significant achievement

The recent price issue aside, the only place you will hear the NZ industry rubbished is in NZ. It is considered by British farmers that we have done a good job in promoting our product and it is acknowledged by some that they have had a free ride on the back of that. People who have been to NZ long to return and others we met wish to come to see the industry that they quite literally hold in awe.

All of this is not to suggest that we are out of the woods, but it does suggest that we are better than we think, and that we can turn our sheep industry into a real winner. The first thing we have to do is bury the hatchet on philosophy and structure. The Meat Board decision to set all of its commercial operations aside from its other activities is the last chapter in that debate.

Castyourmindbacktothecoldwintermomingsyou have spent watching schoolboy rugby. Recall for moment the performance of those teams that kept bickering among themselves - "pass it out" or "tackle him next time." Those teams never win a game and the meat industry is no different. We don't have the game plan that I would have preferred, but the time is long past for the captain to announce that the team we have now is the one we will field. and the tactics we have now are those we will use. This responsibility rests with the Minister of Agriculture. Change can come by process of evolution, but for the immediate future let's stop squabbling over philosophy and structure. If our intention to increase farmer returns is held dearly enough, then it will overcome some deficiencies in structure and some inconsistencies in philosophy. Those who continue the argument prolong the pain.

Three people with various degrees of responsibility in the meat industry indicated to me that anything up to another $\$ 10$ per lamb is available for the $N Z$ farmer. Tha $\$ 10$ would make the world of difference to sheep fanning in this country, yet in the context of the wholemarket it is not so much. One p per lb of lamb on the British market equals $\$ 1.05$ for a $14 \mathrm{~kg}$ lamb. Whether it is in cost savings or better market returns, every $p$ per $1 b$ makes a tremendous difference for us. This begs the question "why?" Why are New Zealand farmers only getting $75 \%$ of what some people see as the potential return for our product? If we are going to keep knocking our own industry and squabbling among ourselves then maybe $75 \%$ is all we deserve. Unfortunately when returns are low, no company can retain the profits necessary to develop markets. This increases our reliance upon agents and foreign importers who are probably more concerned with their own margins than the return to farmers. On continental Europe, 25 agents and 180 importers handle our product. Two importers taking the same product to the same retailer can win business on only one basis - price. It can easily become a downward spiral.

We have all heard travellers returning from UK express disappointment at the appearance of $\mathrm{NZ}$ lamb in the market. I cannot agree with all of this criticism. The chilled product I saw looked extremely attractive and at the equivalent of $\$ 11$ to $\$ 14$ per $1 \mathrm{~b}$ was the most expensive lamb I saw in UK. Compared with other frozen product NZ lamb looked reasonable, but then it is not always compared with frozen product. People buy with their eyes and fresh pork leg at E3.30 per lb looks very attractive beside frozen lamb leg at E6.00 per lb. The consumer is offered a tremendous choice and the choice that we offer is not the cheapest for those who buy on price, nor it is the most appealing to those who buy on impulse. We will have to work harder at making lamb more attractive to the shopper's eye. It can be done. Some frozen lamb that carried a label with some references to this country and its clean environment, as well as cooking instructions, looked the equal of all other products on offer. Butterfly chops in that selection of our product carried a price tag three times that of chicken legs.

The power of the supermarket is not to be underestimated.In parts of England they take $66 \%$ of the product we sell. The four biggest supermarkets in UK have a total turnover equal to our Gross National Product. Payment terms are not always prompt and 60 or even 90 days are considered normal in some parts of the EC. The only way to counter this is to have a product so strongly sought after by consumers that supermarketsmust stock it. This requires considerable promotion and the Meat Board spends about $\$ \mathbf{\$ 3} . \mathbf{3}$ each year promoting NZ Lamb and featuring the rosette trademark. The payoff is that our lamb rosette is the 7th most recognised trademark in the UK. But we cannot afford the nation-wide promotions that have brought $97 \%$ recognition of companies like Birdseye, Bernard Matthews and Kelloggs. Compared with their promotions, our efforts are small. We willhaveto becareful tomaintainthepresentmarket awareness we enjoy.

NZ wool enjoys a reputation for quality too. Price and of course price stability do present some problems. 
I saw British wool going onto a spinning mill. The grower had received about $\$ 3.40$ greasy in spite of obvious black fibre and kemp. Farmers wrap up each fleece with its own belly and pieces inside. These are all opened by the British Wool Marketing Board who grade and repack it. The cost of doing this plus the price to the grower must come to about $\$ 4.00$. Yet the wool I saw was sold to the spinner for about $\$ 2.20$ per $\mathrm{kg}$. which explains why he wasn't using NZ wool.

There was a time when I would have advocated extending the membership of the International Wool Secretariat to indude other wool growing countries. But I am now of the view that we are establishing a deserved reputation for quality for the products of member countries and that it would not be in our interests to involve other producers. It is difficult to assess the performance of organisations like IWS, and no doubt some improve ment is possible. But the fact remains that if we do not support manufacturers in their use of NZ wool, then there are plenty of people prepared to support them in the use of synthetic fibres.

Bureaucratic nonsense plagues British farmers all the time. One man told me that after a full day of studying the application form for oilsecd rape supplementary payments, all he managed to do was write his name and address at the top. And apparently the accuracy of such daims and set aside areas can be checked by satellite. Animal welfare standards are getting to a ridiculous point One paper under discussion was going to bar sheep farmers from catching sheep by the leg and/ or wool. While it is tempting for us to laugh, the people who are setting these standards are our customers too. We will have to put into place a minimum set of standards that we can point to when under critical review, and we will have to expect some prosecutions. The British are by far the most sensitive in this respect and I was left in no doubt that British farmers would ensure that our farm practices would come under the same scrutiny they suffer.

All of this interference leaves the British less able to adapt and innovate. While their research is at least as advanced as ours, the uptake of the technology is much slower. This is an area where we can establish the competitive edge we need to bridge the 10.000 miles of ocean that separates us from our market. When we sell technology or genetic material we should realise that action demands that we move onto the next step to maintain our edge. The more ideas we sell or give away, the more new ones we will have to come up with. Any doubts about this should be referred to a kiwifruit grower.

Of recent years the British sheepfarmer has been as much our compeitor as any producer of beef, pork, or chicken. But the changes which are taking place in the
British sheep industry now may make it more seasonal. If so, there are opportunities for co-operation between the British, who are the world's second largest exporters of sheep meats, and ourselves, with each holding the market open across the other's off season.

Our industry has problems and they are obvious for all to see. but we have much to be proud of. If we could devote just half of the energy to building ourselves up that we do toward knocking ourselves down then we could make significant progress. There are opportunities for a well disciplined sheep industry. 